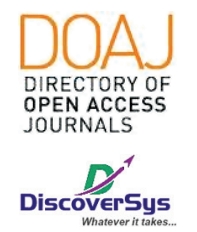

Published by DiscoverSys

\title{
Gambaran klinis akibat intoksikasi metanol pada pasien yang di rawat di RSUP Sanglah Denpasar tahun 2010-2015
}

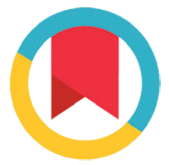

CrossMark

\author{
Khairul Abrar, ${ }^{1 *}$ Dudut Rustyadi ${ }^{2}$
}

\section{ABSTRACT}

Introduction: Methanol is a colorless and odorless with a little chemical formula $\mathrm{CH} 3 \mathrm{OH}$. Methanol is also called methyl alcohol, wood spirit, carbinol, wood alcohol, wood and naphtha. Methanol for consumption was not allowed because methanol is not for consumption and the substances is toxic for the body. Compared to alcohol, methanol has a higher toxic dose. Alcohols toxic dose is $100 \mathrm{mg} / \mathrm{dL}$ and a minimum lethal dose of alcohol is $300 \mathrm{mg} / \mathrm{dL}$, whereas methanol toxic dose of $100 \mathrm{mg} / \mathrm{kg}(10 \mathrm{mg} / \mathrm{dL})$ and letal minimal $300-1000$ dose $\mathrm{mg} / \mathrm{kg}$ body weight $(30-100 \mathrm{mg} / \mathrm{dL}$ ). The main effect of methanol can be intoxicating, metabolic products can cause metabolic acidosis, blindness, and death after a latent period of 6-48 hours.

Method: The research data obtained from the Installation Medical Record Sanglah General Hospital by taking samples of patients suspected methanol poisoning based on medical records of patients in the form of medical records from 2010 to 2015. Sample already obtained 11 patient. Based on the results in this study, clinical organ damage in systemic samples, results of physical examination and lab tests shows that are interrelated. In patients with methanol poisoning can be found some characteristic changes in body organs both in general and microscopic. In almost all patients treated regularly consume alcohol and when it happens poisoning complaints and clinical symptoms are the same. Some disorders such as headache, blurred vision, nausea, vomiting, difficulty breathing often to be found in every case of methanol poisoning.

Conclusion: Symptoms caused by methanol poisoning are systemic, laboratory tests are very important because it provides an overview of the extent of organ damage that occurs.

Keywords: methanol, alcohol poisoning, metabolic acidosis

Cite this Article: Abrar, K., Rustyadi, D. 2020. Gambaran klinis akibat intoksikasi metanol pada pasien yang di rawat di RSUP Sanglah Denpasar tahun 2010-2015. Intisari Sains Medis 11(1): 47-50. D0l: 10.15562/ism.v11i1.541

\section{ABSTRAK}

Latar Belakang: Metanol adalah cairan tidak berwarna dan sedikit berbau dengan rumus kimia $\mathrm{CH}_{3} \mathrm{OH}$. Metanol disebut juga methyl acohol, wood spirit, carbinol, wood alcohol, dan wood naphta. Penggunaan metanol untuk konsumsi tidak lah dibenarkan karena metanol adalah zat tidak layak konsumsi dan beracun bagi tubuh. Dibandingkan alkohol, metanol mempunyai dosis toksik yang lebih tinggi. Dosis toksik alkohol adalah $100 \mathrm{mg} / \mathrm{dL}$ dan dosis letal minimal alkohol adalah $300 \mathrm{mg} / \mathrm{dL}$, sedangkan methanol dosis toksiknya 100 $\mathrm{mg} / \mathrm{kgBB}$ (10 mg/dL) dan dosis letal minimal300-1000 mg/kgBB (30-100 mg/dL). Efek utama metanol dapat memabukkan, produk metaboliknya dapat menyebabkan asidosis metabolik, kebutaan, dan kematian setelah periode laten 6-48 jam.

Metode: Data penelitian didapatkan dari Instalasi Rekam Medis RSUP Sanglah dengan mengambil sampel pasien yang diduga keracunan metanol berdasar catatan medis pasien dalam bentuk data rekam medis dari tahun 2010 hingga 2015. Didapatkan sampel yang memenuhi kriteria inklusi dan ekslusi sebanyak 11 pasien.

Hasil: Berdasarkan hasil dan pembahasan pada penelitian ini, maka dapat ditarik kesimpulan bahwa Gambaran Klinis kerusakan organ pada sampel bersifat sistemik, Hasil pemeriksaan fisik dan pemeriksaan lab menunjukan hasil yang saling terkait. Pada pasien keracunan metanol bisa ditemui beberapa karakteristik perubahan asam-basa dalam tubuh baik. Pada hampir keseluruhan pasien yang di rawat rutin mengkonsumsi alcohol dan ketika terjadi keracunan memiliki keluhan dan gejala klinis yang sama. Beberapa gangguan seperti Nyeri kepala, penglihatan kabur, mual, muntah, hingga susah bernapas seringkali di temukan pada setiap kasus keracunan metanol. Simpulan: Gejala yang diakibatkan oleh keracunan methanol bersifat sistemik, pemeriksaan laboratorium sangat penting dilakukan karena memberikan gambaran sejauh mana kerusakan organ tubuh yang terjadi. 


\section{PENDAHULUAN}

Miras mengandung zat psikoaktif yang menyebabkan kecanduan pada penggunanya. Konsumsi miras berlebih dalam jangka panjang dapat menimbulkan efek keracunan. Efek konsumsi miras dalam jumlah banyak dan jangka waktu lama antara lain mengakibatkan kerusakan hati, gangguan neurologis, gangguan kardiovaskuler, gangguan jiwa, dan kanker. Konsumsi miras dikaitkan dengan risiko masalah kesehatan seperti ketergantungan alkohol, sirosis hati, kanker, kecelakaan, dan cedera. ${ }^{1,2}$

Minuman-minuman beralkohol yang biasa disebut miras oleh masyarakat, merupakan topik yang banyak dibicarakan saat ini. Topik ini seputar miras yang dioplos sedemikian rupa sehingga mengandung zat-zat yang sangat berbahaya bagi tubuh. Terbukti dengan adanya kasus di wilayahwilayah sekitaran bali yang menimbulkan korban bahkan sampai meninggal dunia. Di Bangli, karena mengonsumsi arak yang diduga dioplos dengan metanol, korban mencapai 27 orang dan tiga diantaranya meninggal dunia. Tidak hanya warga lokal yang menjadi korban, warga negara australia dilaporkan meninggal di wilayah seminyak, kuta bali.

Banyak jenis miras bisa didapat dengan mudah di masyarakat. Mulai dari arak tradisional yang cukup terjangkau untuk di didapatkan, sampai miras berlabel mencapai harga jutaan rupiah. Untuk mendapatkan arak tradisional dapat di beli di warung-warung dan kios-kios jamu, sedangkan miras berlabel bisa didapat di pusat-pusat perbelanjaan, supermarket, kafe, maupun tempat hiburan malam. Banyak masyarakat yang mencampur miras dengan beberapa zat yang berbahaya bagi tubuh agar memberikan efek yang lebih sesuai dengan yang mereka inginkan, karena jika untuk mendapat minuman bermerek yang mengandung alkohol tinggi, perlu mengeluarkan biaya yang tidak sedikit. Akibatnya, banyak kecurangan yang dilakukan pembuat oplosan demi mendapatkan untung yang banyak dengan cara mencampur alkohol konsumsi dengan bahan lain seperti methanol. Fenomena ini menjadi dasar dari maraknya miras yang disebut miras oplosan.

Miras adalah jenis minuman yang mengandung ethanol $\left(\mathrm{C} 2 \mathrm{H} 5 \mathrm{OH}\right.$, ethyl alcohol). ${ }^{3,4}$ Harga minuman beralkohol yang mempunyai izin sah sangat mahal karena adanya pajak yang cukup tinggi. Adanya pajak ini sebenarnya untuk membatasi peredaran dari minuman beralkohol di masyarakat. Namun masyarakat telah mengenal minuman ini dari zaman dahulu. Dari yang pembuatannya tradisional hingga pabrikan.

Pada tahun 2014, WHO melaporkan 38,3\% penduduk di dunia di atas 15 tahun telah mengkonsumsi miras dalam 12 bulan terakhir. Angka konsumsi per kapita di seluruh dunia mencapai 6,2 liter dan terus meningkat. Proporsi pemakaian miras di Indonesia sendiri mencapai 0,6 liter per kapita. Hal ini dipengaruhi oleh meningkatnya status sosial ekonomi sebagian besar penduduk, mulai munculnya budaya minum alkohol, dan semakin mudahnya akses untuk mendapatkan miras secara bebas., ${ }^{5,6}$ Zat-zat yang sering digunakan untuk mencampur atau mengoplos miras adalah methanol, obat lotion untuk pencegah serangga, minuman berenergi, minuman bersoda, kopi, bahan pewarna, dan bahan perasa.

Pada penelitan ini diteliti gambaran klinis tubuh akibat efek konsumsi miras oplosan yang mengandung methanol, dan hasil pemeriksaan laboratorium pada pasien-pasien yang dirawat di RSUP Sanglah Denpasar.

\section{METODE}

Metode yang akan digunakan dalam penelitian ini adalah deskriptif cross-sectrional yang dilakukan dari bulan Oktober 2016 hingga Januari 2017, data rekam medis yang digunakan sebagai sumber adalah pada rentangan tahun 2010 hingga 2015. Karakteritsik yang dilakukan penjabaran dalam penelitian ini adalah usia, jenis kelamin, gejala yang dialami, dan hasil analisis gas darah yang diambil melalui sampel darah arteri. Data kemudian disajikan dalam bentuk tabel secara deskriptif.

\section{HASIL DAN PEMBAHASAN}

Tujuan dari penelitian ini adalah memberikan gambaran gejala klinis dan pada pasien yang di rawat akibat intoksikasi methanol beserta hasil dari pemeriksaan labnya. Karakteristik sampel dapat dilihat pada Tabel 1.

Dari variabel jenis kelamin didapatkan 75\% laki-laki dan $25 \%$ perempuan. berdasarkan data dari International Alcohol Soicety (IAS) tahun 2013 menyebutkan bahwa konsumsi miras pada laki-laki dua kali lebih banyak dari perempuan dengan rasio 15.6 dibanding 7.8. Namun presentase yang berbeda antara laki-laki dan perempuan pada penelitian ini, dikarenakan jumlah sampel yang sedikit sehingga tidak bisa mewakili populasi.

Tidak ada sampel keracunan metanol pada anak, hal ini sesuai dengan data menurut WHO tahun 2011 yang menyatakan bahwa konsumsi miras dilakukan oleh orang dengan umur 15 tahun ke atas. Pada data kelompok umur 15-20 tahun di dapatkan sebesar $18 \%$, umur $41-60$ sebesar $27 \%$, Puncak konsumsi miras pada penelitian ini terjadi pada kelompok dewasa berumur 21-60 tahun dan tidak didapatkan data untuk sampel berumur lebih 
Tabel 1 Karakteristik Umum

\begin{tabular}{lcc}
\hline Variabel & Nilai & $\%$ \\
\hline Jenis Kelamin & & \\
Laki-laki & 8 & $75 \%$ \\
Perempuan & 3 & $25 \%$ \\
Umur & & \\
$15-20$ tahun & 2 & $18 \%$ \\
$21-40$ tahun & 6 & $55 \%$ \\
$41-60$ tahun & 3 & $27 \%$ \\
$>60$ tahun & 0 & $0 \%$ \\
\hline
\end{tabular}

Tabel 2 Hasil Temuan Pemeriksaan Fisik

\begin{tabular}{lcc}
\hline Gejala Klinis & Frekuensi & $\%$ \\
\hline Gangguan pengelihatan & 8 & $75 \%$ \\
Mual, muntah, dan nyeri perut & 11 & $100 \%$ \\
Sesak napas & 11 & $100 \%$ \\
Pusing, letargi, penurunan kesadaran & 11 & $100 \%$
\end{tabular}

Tabel 3 Gambaran hasil analisis gas darah

\begin{tabular}{lcccc}
\hline Pasien & $\mathbf{P h}$ & $\mathbf{P a C O}_{\mathbf{2}}$ & $\mathbf{S a O}_{\mathbf{2}}$ & $\mathbf{H C O 3 -}$ \\
\hline $\mathrm{A}$ & 7,0 & 40,2 & 97,3 & 21,30 \\
$\mathrm{~B}$ & 7,1 & 45,2 & 98,8 & 26,20 \\
$\mathrm{C}$ & 7,48 & 31 & 99 & 19,6 \\
$\mathrm{D}$ & 7,4 & 32,1 & 99 & 19,41 \\
$\mathrm{E}$ & 7,18 & 33 & 98 & 19,4 \\
$\mathrm{~F}$ & 7,1 & 39 & 96 & 19,2 \\
$\mathrm{G}$ & 7,3 & 33,4 & 95 & 20 \\
$\mathrm{H}$ & 7,2 & 36 & 95 & 19,1 \\
$\mathrm{I}$ & 7,4 & 20 & 97,1 & 18 \\
$\mathrm{~J}$ & 7,25 & 39 & 97 & 19,3 \\
$\mathrm{~K}$ & 7,2 & 30 & 98 & 18 \\
\hline
\end{tabular}

dari 60 tahun. Hal tersebut sesuai dengan data dari Foundation for Alcohol Research and Education tahun 2014 yang menyatakan bahwa orang berumur 60-64 tahun, memilih tidak mengonsumsi miras karena kesehatan yang buruk.

Keseluruhan sampel pada penelitian ini merupakan WNI. kurangnya sampel pada penelitian ini dikarenakan banyak yang tidak memenuhi kriteria inklusi dan eksklusi. hal ini di karenakan data yang diperoleh sangatlah terbatas.

Hasil temuan pada penelitian ini di dapatkat 8 pasien yang di rawat mengalami gangguan penglihatan dengan persentase 75\% (Tabel 2). Ganguan penglihatan, termasuk menurunnya ketajaman penglihatan yang berhubungan dengan asidosis metabolic dan penurunan respon cahaya dan reflek pada pupil, walaupun pada sebagian pasien gangguan visus ini dapat kembali normal. Pada pemeriksaan funduskopi di dapatkan hiperemis dan edema diskus optikus, peripapilari edema retina. ${ }^{7,8}$

Mual, muntah dan nyeri perut ditemukan dari semua pasien diduga keracunan methanol yang didapatkan dan juga pasien mengalami keluhan pernapasan usai mengkonsumsi metanol. Nyeri kepala, vertigo, lemas, dan bingung juga ditemukan, hal ini menunjukan adanya edem pada otak..$^{9,10}$

Intepretasi analisis gangguan asam basa dapat diketahui berdasarkan jumlah $\mathrm{PH}, \mathrm{PCO}$, dan HCO3. Dalam pelnelitian ini di dapatkan pada pasien A $\mathrm{PH}=7.0, \quad \mathrm{PCO} 2=40.2, \quad \mathrm{HCO} 3=21.30$ menunjukan telah terjadi gangguan Asidosis Metabolik tanpa kompensasi. Pasien B $\mathrm{PH}=7.4$, $\mathrm{PCO} 2=45.2, \quad \mathrm{HCO} 3=26.20$ menunjukan telah terjadi gangguan Asidosis Respiratorik tanpa kompensasi. Pasien C $\mathrm{PH}=7.48, \quad \mathrm{PCO} 2=31$, HCO3=19.6 menunjukan telah terjadi gangguan Alkalosis respiratory dengan kompensasi. Pasien D $\mathrm{PH}=7.4, \mathrm{PCO} 2=32.1, \mathrm{HCO} 3=19.41$ menunjukan telah terjadi gangguan Asodosis Metabolik dengan kompensasi. Pasien E $\mathrm{PH}=7.18, \mathrm{PCO} 2=33$, HCO3=19.4 menunjukan telah terjadi gangguan Metabolik asidosis terkompensasi sebagian Alkalosis Metabolik. Pasien F PH=7.1, PCO2=39, $\mathrm{HCO} 3=19.2$ menunjukan terjadi gangguan Metabolik Asidosis tanpa kompensasi. Pasien G $\mathrm{PH}=7.3, \mathrm{PCO} 2=33.4, \mathrm{HCO} 3=20$ menunjukan telah terjadi gangguan Metabolik Asidosis terkompensasi sebagian Alkalosis respiratorik. Pasien $\mathrm{H} \mathrm{PH}=7.2$, $\mathrm{PCO} 2=36, \mathrm{HCO} 3=19.1$ menunjukan telah terjadi gangguan Metabolik Asidosis tanpa kompensasi. Pasien I PH=7.4, PCO2=20, $\mathrm{HCO} 3=19.3$ menunjukan telah terjadi gangguan Metabolik Asidosis terkompensasi sebagian Alkalosis Respiratori. Pasien J PH=7.25, $\mathrm{PCO} 2=39, \mathrm{HCO} 3=19.3$ menunjukan telah terjadi gangguan Metabolik Asidosis tanpa kompensasi. Pasien $\mathrm{K} \mathrm{PH}=7.2, \mathrm{PCO} 2=30$, $\mathrm{HCO} 3=18$ menunjukan telah terjadi gangguan Metabolik Asidosis terkompensasi Alkalosis Respiratori (Tabel 3).

\section{SIMPULAN}

Banyak masyarakat yang mengkonsumsi miras dan mencampurkan minumannya dengan methanol, ini karena sifat metanol yang dapat memabukkan, masyarakat menggunakan metanol untuk dicampur dengan etanol agar dapat memberikan efek sesuai dengan yang mereka inginkan. Pencampuran metanol pada etanol memanjangkan periode laten toksistas metanol sehingga apa bila di konsumsi oleh masyarakat, dapat mengakibatkan terjadinya gangguan-gangguan akut pada tubuh. 


\section{KONFLIK KEPENTINGAN}

Penulis menyatakan tidak memiliki konflik kepentingan terkait publikasi dari artikel ini.

\section{PENDANAAN}

Penelitian ini tidak mendapatkan pendanaan dari pemerintah ataupun lembaga swasta lainnya.

\section{ETIKA DALAM PENELITIAN}

Penelitian ini telah mendapatkan persetujuan dari Komite Etik Fakultas Kedokteran Universitas Udayana/RSUP Sanglah Denpasar dengan nomer referensi 1899/UN14.2.2.VII.14/LP/2018.

\section{DAFTAR PUSTAKA}

1. Baan R, Straif K, Grosse Y, Secretan B, El Ghissassi F, Bouvard V, Altieri A, Cogliano V. Carcinogenicity of alcoholic beverages. Lancet Oncol. 2007;8:292-293

2. Kraut JA, Krutz I. Toxic Alcohol Ingestion: Clinical features, Diagnosis and Management. Clin J Am Soc Nephrol. 2008;3:208-225

3. Andresen H. Schmoldt J, Matschke FA, Flachskamp EE. Fatal methanol intoxication with different survival timesMorphological findings and postmortem methanol distribution. Forensic Science International. 2008;179:206-210
4. Darwish A, Roth CE, Duclos P, Ohn SA, Nassar A, Mahoney F, Vogt R, and Arthur RR. Investigation into a cluster of infant deaths following immunization: evidence for methanol intoxication. Vaccine. 2002;20:3585-9.

5. Eells JT, Makar AB, Noker PE, Tephly TR. Methanol Poisoning and Formate Oxidation in Nitrous OxideTreated Rats. J Pharmacol Exp Ther. 1981;217:57-61.

6. Martin-Amat G, Tephly TR, McMartin KE, et al. Methyl alcohol poisoning II. Development of a model for ocular toxicity in methyl alcohol poisoning using the Rhesus monkey. Arch Ophthalmol. 1977;95:1847-1850.

7. Noker PE, Eells JT, Tephly TR. Methanol toxicity: Treatment with folic acid and 5-formyl tetrahydrofolic acid. Alcoholism: Clin Exp Res. 1980;4:378-383.

8. Nicholls, P. The Effect of Formate on Cytochrome aa3 and on Electron Transport in the Intact Respiratory Chain. Biochim Biophys Acta. 1976;430:13-29.

9. Sejersted OM, Jacobsen D, Øvrebø S, Jansen H. Formate Concentrations in Plasma from Patients Poisoned with Methanol. Acta Med Scand. 1983;213:105-110.

10. Shelby M, Portier C, Goldman L, Moore J, Iannucci A, Jahnke G, Donkin S. NTP-CERHR expert panel report on the reproductive and developmental toxicity of methanol. Reprod Toxicol. 2004; 18:303-90.

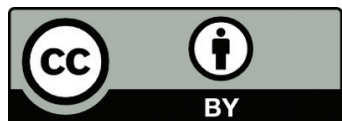

This work is licensed under a Creative Commons Attribution 